\title{
CMR adenosine stress perfusion in pediatrics and congenital heart disease: effects on clinical decision making and outcomes
}

\author{
Michael J Campbell ${ }^{1,2 *}$, Piers Barker ${ }^{1,2}$, Brenda Hayes ${ }^{2}$, Raymond J Kim² \\ From 15th Annual SCMR Scientific Sessions \\ Orlando, FL, USA. 2-5 February 2012
}

\section{Background}

In contrast to adults with coronary artery disease (CAD), the use of CMR adenosine stress perfusion in pediatrics and in adults with congenital heart disease (CHD) is not well established. The medical literature reveals an absence of experience evaluating the effects of CMR adenosine stress perfusion on clinical decision making and outcomes in these populations.

\section{Specific Aims}

Evaluate whether CMR adenosine stress perfusion in pediatrics and adults with CHD affects clinical decision making and outcomes.

\section{Methods}

Consecutive patients, who completed CMR adenosine stress perfusion and were $<21$ yo or $>21$ yo with CHD, were enrolled. SSFP cine and delayed enhancement CMR (DE-CMR) were performed in a standard manner. Adenosine stress perfusion was performed with administration of adenosine $(140 \mathrm{ug} / \mathrm{kg} / \mathrm{min})$ for $2-4$ minutes and gadolinium $(0.1 \mathrm{mmol} / \mathrm{kg})$ using a standard adult protocol. Perfusion defects matching infarct size on DECMR and defects corresponding to DE-CMR at the right ventricular insertion site or post-surgical changes were considered negative for ischemia.

\section{Results}

51 studies were performed in 46 patients (mean 25.6 years, $32<21$ years). Diagnoses and symptoms are listed in Tables 1 and 2. 40/51 studies were negative for ischemia and this finding resulted in no further imaging in

${ }^{1}$ Pediatrics, Duke University Medical Center, Durham, NC, USA

Full list of author information is available at the end of the article
37/40 (93\%). 3 patients underwent coronary angiography despite the absence of ischemia on stress perfusion, and none had coronary artery stenosis. 11/51 studies revealed ischemia and 8 were consistent with CAD. 3 patients with ischemia were diagnosed with hypertrophic cardiomyopathy (HCM) based on a) ischemia pattern with small punctate perfusion defects in the mid-portion of the ventricular septum, b) other morphologic findings of HCM. A finding of ischemia led to coronary angiography in 7/10 (1 lost to follow-up). The patients who did not undergo coronary angiography had HCM. 5/7 who underwent coronary angiography had coronary artery stenosis in a pattern consistent with stress perfusion findings. Of these 5 patients, 2 have undergone or are scheduled for coronary artery bypass graft (CABG), 1 is listed for cardiac transplant (pulmonary atresia/ intact ventricular septum status post Fontan), 1 is undergoing further workup (myocardial bridge) and 1 was lost to follow-up. Survival rate is $100 \%$. The 3 patients with ischemia in the setting of HCM have been restricted from competitive athletics.

\section{Conclusions}

A negative finding on CMR adenosine stress perfusion often results in no further testing, indicating confidence in the result. A positive result can lead to further workup and positively affect patient outcomes.

\section{Funding}

Institutional.

Author details

'Pediatrics, Duke University Medical Center, Durham, NC, USA. ²Duke Cardiovascular Magnetic Resonance Center, Duke Unviersity Medical Center, Durham, NC, USA. 
Table 1 Diagnoses

\begin{tabular}{|c|c|}
\hline Kawasaki disease & \\
\hline Tetralogy of Fallot status post repair & \\
\hline Hypertrophic cardiomyopathy & \\
\hline Suspected hypertrophic cardiomyopathy & \\
\hline $\begin{array}{c}\text { Anomalous left coronary artery arising from pulmonary artery- } \\
\text { repaired }\end{array}$ & \\
\hline Left coronary artery arising from the right coronary sinus-repaired & \\
\hline Aortic stenosis status post Ross operation & \\
\hline Ventricular septal defect status post repair & \\
\hline Coarctation of the aorta status post surgical repair & \\
\hline Right coronary artery arising from the left coronary sinus-repaired & \\
\hline $\begin{array}{l}\text { Anomalous right coronary artery arising from the pulmonary artery- } \\
\text { repaired }\end{array}$ & \\
\hline Pseudoxanthoma elasticum & \\
\hline Pulmonary atresia with intact ventricular septum & \\
\hline $\begin{array}{c}\text { Transposition of the great arteries status post arterial switch } \\
\text { operation }\end{array}$ & \\
\hline Transposition of the great arteries status post Mustard operation & \\
\hline Coarctation of the aorta status post transcatheter stent & \\
\hline Bicuspid aortic valve and HTN & \\
\hline Right coronary artery aneurysm, etiology unknown & \\
\hline Myocardial bridge & \\
\hline Scimitar syndrome status post repair and coronary artery bypass graft & \\
\hline Congenitally corrected transposition of the great arteries & \\
\hline Hypoplastic right pulmonary artery, hypoplastic right coronary artery & \\
\hline Dysplastic pulmonary valve with pulmonary insufficiency & \\
\hline $\begin{array}{c}\text { Sinus venosus atrial septal defect and partial anomalous pulmonary } \\
\text { venous return-repaired }\end{array}$ & \\
\hline
\end{tabular}

\section{Table 2 Presenting Symptom}

Chest pain

Previous abnormal diagnostic test

Asymptomatic, screening

Dyspnea

Syncope

Nausea and fatigue

Irritability

\section{9}

13

11

3

3

1

1

Published: 1 February 2012

doi:10.1186/1532-429X-14-S1-060

Cite this article as: Campbell et al: CMR adenosine stress perfusion in pediatrics and congenital heart disease: effects on clinical decision making and outcomes. Journal of Cardiovascular Magnetic Resonance 2012 14(Suppl 1):060.

\section{Submit your next manuscript to BioMed Central and take full advantage of:}

- Convenient online submission

- Thorough peer review

- No space constraints or color figure charges

- Immediate publication on acceptance

- Inclusion in PubMed, CAS, Scopus and Google Scholar

- Research which is freely available for redistribution

Submit your manuscript at www.biomedcentral.com/submit 